\title{
Abolition by omeprazole of aspirin induced gastric mucosal injury in man
}

\author{
T K Daneshmend, A G Stein, N K Bhaskar, C J Hawkey
}

\begin{abstract}
This study investigates whether aspirin injury to the human gastric mucosa can be prevented by profound acid suppression with omeprazole, in a randomised, double blind, crossover design according to latin square. It was concluded that profound acid suppression can prevent aspirin induced gastric mucosal injury in normal subjects. This approach may prevent the development of peptic ulcers and their complications in patients taking aspirin and other non-steroidal anti-inflammatory drugs.
\end{abstract}

Aspirin and non-steroidal anti-inflammatory drugs are strongly associated with peptic ulcer complications in the elderly in Britain. ${ }^{1-5}$ Assuming that the association may be causative, a number of approaches have tried to reduce the extent of damage caused by these agents. Although old people appear to be at greatest risk, it is difficult to evaluate possible therapeutic manoeuvres in this population. We have therefore investigated healthy adult volunteers whose acute responses appear to reflect those of older patients. ${ }^{7}$ Our previous studies show that acid inhibition by ranitidine ${ }^{8}$ and famotidine ${ }^{9}$ results in a reduction in gastric mucosal damage, as quantified by the rate of gastric mucosal bleeding and endoscopic appearance, but aspirin induced damage was not totally abolished.

In the present study we have examined the hypothesis that gastric acid is necessary for the occurrence of aspirin induced gastric damage. To achieve virtual gastric anacidity we used omeprazole, an irreversible inhibitor of the proton pump in gastric parietal cells. ${ }^{10}$

\section{Methods}

SUBJECTS

Sixteen healthy non-smoking adults (eigh men; age range 19-25 years) were studied. They took no regular medication, except the contraceptive pill. All had normal biochemical and haematological values, including platelet count, prothrombin time and activated partial thromboplastin time. The study was approved by the Nottingham Medical School Ethical Committee and subjects gave written informed consent.

University Department Therapeutics, University Hospital, Nottingham T K Daneshmend A G Stein N K Bhaskar C J Hawkey

Correspondence to: Dr T K Daneshmend, Dept of Medicine, Royal Devon and Exeter Hospital, Wonford Barrack Road, Exeter EX2 5DW.

Accepted for publication 10 August 1989
Gastric blood loss was measured in each subject on four occasions, at the end of each of the following regimens: (a) placebo omeprazole plus placebo aspirin, both for seven days; (b) placebo omeprazole for seven days plus aspirin $900 \mathrm{mg}$ bd for the last $48 \mathrm{~h}$; (c) omeprazole $20 \mathrm{mg}$ each morning for seven days plus aspirin $900 \mathrm{mg}$ bd for the last $48 \mathrm{~h}$; and (d) omeprazole $40 \mathrm{mg}$ bd for seven days plus aspirin $900 \mathrm{mg}$ bd for the last $48 \mathrm{~h}$. The last doses of omeprazole and aspirin (or the corresponding placebo) were taken at $0700 \mathrm{~h}$ and $0730 \mathrm{~h}$ - that is, 120 and 90 minutes, respectively, before measurement of gastric blood loss. Each of the above regimens was separated by a seven day washout period. The order of treatments was randomised according to a latin square design and the study conducted in double blind manner.

\section{SAMPLE COLLECTION}

Gastric blood loss was determined after an overnight fast, the final doses being taken at $0700 \mathrm{~h}$ and $0730 \mathrm{~h}$ on the study day. At $0900 \mathrm{~h}$ each subject swallowed a 16 French gauge Salem sump orogastric tube. After aspiration of resting gastric juice, the stomach was rinsed three times with distilled water (not a glucose solution) as originally described by Hunt." The first of three 10 minute study periods then commenced. Half way during each period phenol red $(2 \mathrm{mg}$ in $15 \mathrm{ml}$ water) was introduced through the orogastric tube and dispersed around the stomach. After nine minutes, distilled water $100 \mathrm{ml}$ was introduced, dispersed and then aspirated by 10 minutes. After two more rinses a second 10 minute study period started, and after two further rinses there was a third 10 minute study period. The subjects were recumbent on their left side to reduce pyloric loss of gastric contents, except when liquids were introduced into the stomach when a standard series of manoeuvres was performed in order to ensure maximal contact with the gastric mucosa.

\section{ASSAYS}

The $\mathrm{pH}$ of resting gastric juice and gastric washings was measured immediately after collection using a glass electrode (Corning). The volume of blood in gastric aspirates was quantified by the peroxidase activity of haemoglobin, using the orthotolidine reaction. ${ }^{112}$ Briefly, samples in citrate buffer were mixed with orthotolidine. The rate of development of a blue colour was determined on a spectrophotometer at $640 \mathrm{nmol}$ between 30 and $60 \mathrm{sec}$ after addition of hydrogen peroxide. This was compared with values from a standard curve constructed using the subjects own blood. Gastric blood loss was expressed as $\mu \mathrm{l}$ of blood/10 min period after correction for phenol red recovery. The median value from the three 10 minute periods was used for analysis. Phenol red concentration in gastric aspirates obtained during the study periods was 
TABLE Gastric mucosal blood loss, $p H$ of resting juice, $p H$ of gastric washings and phenol red recovery in 16 subjects after (a) placebo only, (b) aspirin $900 \mathrm{mg}$ bd only, (c) aspirin $900 \mathrm{mg}$ bd plus omeprazole $20 \mathrm{mg}$ mane, and (d) aspirin $900 \mathrm{mg}$ bd plus omeprazole $40 \mathrm{mg}$ bd

\begin{tabular}{|c|c|c|c|c|}
\hline & Placebo & Aspirin & $\begin{array}{l}\text { Aspirin plus } \\
\text { Omeprazole } 20 \text { mg mane }\end{array}$ & $\begin{array}{l}\text { Aspirin plus } \\
\text { Omeprazole } 40 \mathrm{mg} \text { bd }\end{array}$ \\
\hline $\begin{array}{l}\text { Gastric musocal blood loss } \mu \mathrm{l} / 10 \mathrm{~min} \\
\text { geometric mean }(95 \% \mathrm{CI}) \\
\text { Initial pH median (lower-upper quartiles) } \\
\text { Gastric aspirate pH median (lower-upper }\end{array}$ & $\begin{array}{l}1 \cdot 4(0 \cdot 8-2 \cdot 4) \\
3 \cdot 12(2 \cdot 07-2 \cdot 93)\end{array}$ & $\begin{array}{l}16 \cdot 1(9 \cdot 5-27 \cdot 5)^{\star} \\
3 \cdot 12(2 \cdot 31-5 \cdot 19)\end{array}$ & $\begin{array}{l}3 \cdot 4(1 \cdot 4-5 \cdot 2) \dagger \\
6 \cdot 01(4 \cdot 25-7 \cdot 32) \emptyset\end{array}$ & $\begin{array}{l}2 \cdot 4(1 \cdot 3-4 \cdot 4) \ddagger \\
6 \cdot 60(4 \cdot 91-7 \cdot 16) \oint\end{array}$ \\
\hline $\begin{array}{l}\text { quartiles) } \\
\text { Phenol red recovery }(\%) \text { mean }(\mathrm{SD})\end{array}$ & $\begin{array}{l}2 \cdot 43(1 \cdot 94-2 \cdot 53) \\
54 \cdot 6(11 \cdot 5)\end{array}$ & $\begin{array}{l}2 \cdot 26(2 \cdot 11-2 \cdot 58) \\
57 \cdot 6(9 \cdot 7)\end{array}$ & $\begin{array}{l}3 \cdot 07(2 \cdot 66-6 \cdot 52) \\
63 \cdot 4(13 \cdot 1)\end{array}$ & $\begin{array}{l}6 \cdot 65(5 \cdot 59-6 \cdot 88) \S \\
61 \cdot 1(11 \cdot 0)\end{array}$ \\
\hline
\end{tabular}

${ }^{\star} \mathrm{p}<0.01$ compared with placebo; $\nmid \mathrm{p}<0.01$ compared with aspirin alone; $\ddagger \mathrm{p}<0.001$ compared with aspirin plus $\Theta \mathrm{meprazole} 20 \mathrm{mg} / \mathrm{day}$, and NS compared with placebo; $\{\mathrm{p}<0.01$ compared with placebo.

measured spectrophotometrically at $560 \mathrm{nmol}$, after adjustment of $\mathrm{pH}$ to $10 \cdot 5$ with sodium hydroxide.

\section{STATISTICAL METHODS}

Analysis of variance was used to assess the influence of aspirin and of omeprazole on gastric mucosal bleeding. To approximate to a normal distribution, these data were logarithmically transformed before computation and results given as geometric mean with $95 \%$ confidence limits. Phenol red recovery data were analysed in similar manner, but without logarithmic transformation. Results are expressed as mean and standard deviation (SD). Friedman two way analysis of variance by ranks was used to assess the significance of changes in $\mathrm{pH}$ values and results expressed as medians and interquartile ranges.

\section{Results}

The rate of gastric mucosal bleeding after aspirin was over 10 -fold greater than that after placebo $(\mathrm{p}<0.001)$ (Table and Figure). The value after aspirin plus omeprazole $20 \mathrm{mg} /$ day was reduced significantly by $79 \%$ when compared with that after aspirin alone $(p<0.01)$. Omeprazole $40 \mathrm{mg}$ bd plus aspirin resulted in a gastric mucosal bleeding rate that was $85 \%$ less than after aspirin alone $(p=0.001)$, and although the mean value was slightly higher than placebo, this difference was not significant $(p=0 \cdot 07)$.

The effects of omeprazole on the $\mathrm{pH}$ of resting juice or of gastric washings are shown in the Table. The median initial $\mathrm{pH}$ was unaffected by aspirin $(p=0.79)$; but increased significantly with omeprazole $20 \mathrm{mg} /$ day and $40 \mathrm{mg}$ bd $(\mathrm{p}=0.035$ and $\mathrm{p}<0.001$, respectively compared with placebo). The median initial $\mathrm{pH}$ was not significantly different between the two omeprazole dose regimens $(\mathrm{p}=0 \cdot 4)$. The median $\mathrm{pH}$ of gastric washings is also given in the Table. The only notable difference was a lower $\mathrm{pH}$ with the lower omeprazole dose, while $\mathrm{pH}$ of washings remained at the initial value on the higher omeprazole dose, a difference which was significant $(p<0.01)$. Overall, the reduction in gastric mucosal bleeding rate was significantly correlated with the $\mathrm{pH}$ of initial gastric aspirates $(\mathrm{r}=0.423, \mathrm{p}<0.02)$.

\section{Discussion}

Endoscopic observations implicating aspirin in the pathogenesis of iatrogenic gastric damage were made by Douthwaite and Lintott half a century ago. ${ }^{13}$ The subsequent widespread use of aspirin and other non-steroidal antiinflammatory drugs has been implicated in peptic ulcer perforation rates in Britain. ${ }^{+}$ Emergency admission because of bleeding from gastric and duodenal ulcers in the elderly is

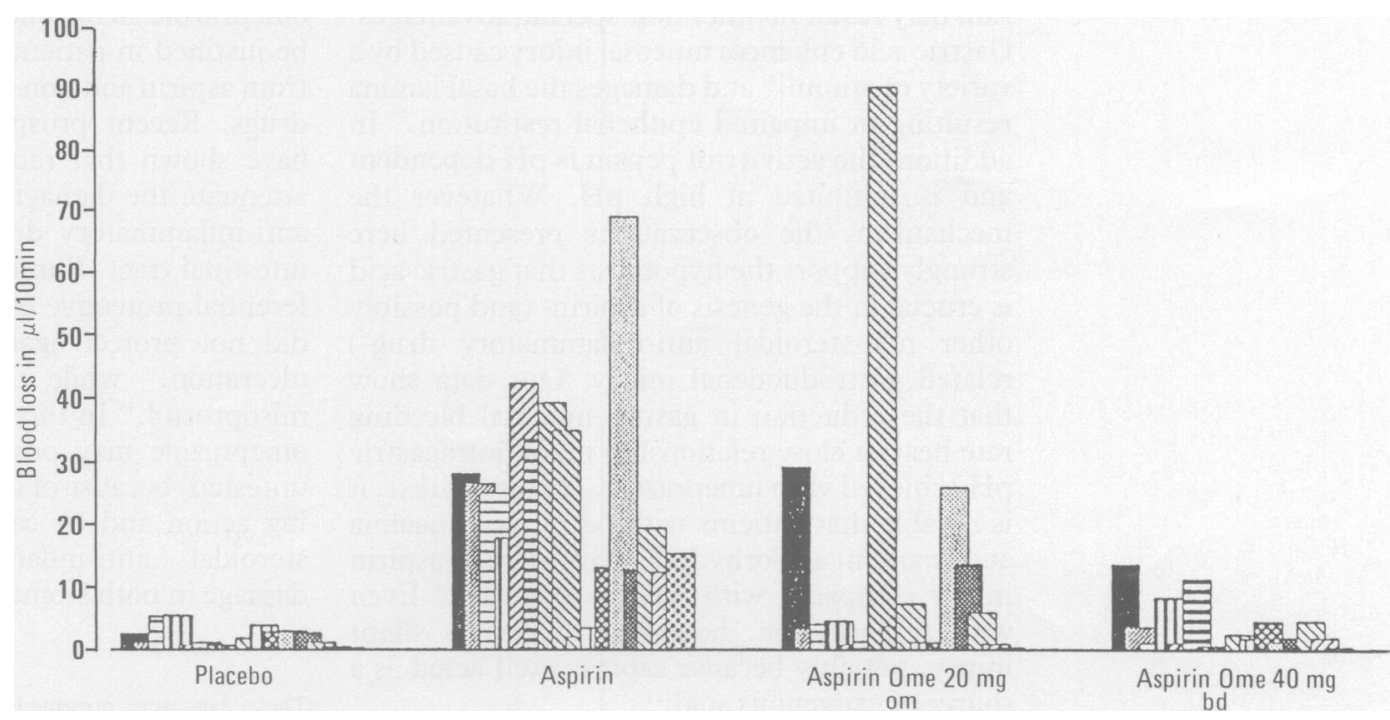

Figure: Individual rates of gastric mucosal blood loss ( $\mu$ l/10 min) in 16 normal adults on placebo, aspirin $900 \mathrm{mg}$ bd only, aspirin $900 \mathrm{mg}$ bd plus omeprazole $20 \mathrm{mg}$ each morning, and aspirin $900 \mathrm{mg}$ bd plus omeprazole $40 \mathrm{mg}$ bd. 
associated with aspirin and other non-steroidal anti-inflammatory drug use in our hospital population. ${ }^{1314}$ Aspirin ingestion is associated with a relative risk of three, even for short periods of exposure. ${ }^{1+4}$ Moreover, aspirin can provoke gastric mucosal bleeding at doses of up to $75 \mathrm{mg}$ taken daily for five days or less. ${ }^{15}$ It is evident that aspirin is probably responsible for a spectrum of damage, ranging from acute gastric erosions to peptic ulcer complications.

In our present study aspirin induced gastric mucosal damage (as quantified by gastric mucosal blood loss) was abolished by omeprazole $40 \mathrm{mg}$ bd, a dose that produces virtual anacidity. ${ }^{16}$ Quantification of gastric mucosal injury by measurement of gastric mucosal blood loss closely reflects direct endoscopic evidence of mucosal damage: we have previously shown gastric mucosal blood loss to correlate with the extent of petechial haemorrhage seen endoscopically. ${ }^{9}$ Our findings accord with a small endoscopic study recently reported in abstract form which showed prevention by omeprazole of gastric injury after a single aspirin dose. ${ }^{17}$

The dissociation constant $(\mathrm{pKa})$ of aspirin is 3.5 . Thus at the levels of intragastric $\mathrm{pH}$ achieved with omeprazole in our study, aspirin ionisation is virtually complete. In this form passive absorption of aspirin into the gastric mucosa does not occur. ${ }^{18}$ In contrast, at normal intragastric $\mathrm{pH}$ aspirin is almost entirely unionised and able to diffuse passively into cells of the gastric epithelium where a neutral $\mathrm{pH}$ results in reionisation and intracellular trapping of salicylate in high concentrations. The consequent topical toxicity of salicylates is well recognised and results in impaired barrier function, reduced mucus and bicarbonate secretion, and capillary injury. ${ }^{1920}$ The underlying metabolic changes are not firmly established, but in the presence of acid aspirin may achieve intracellular levels sufficient to uncouple oxidative phosphorylation or interfere with carbohydrate metabolism. ${ }^{21}$ As most other non-steroidal antiinflammatory drugs are weak acids, similar considerations are likely to apply although direct evidence is lacking.

Apart from these specific benefits, acid inhibition may result in other non-specific advantages. Gastric acid enhances mucosal injury caused by a variety of stimuli ${ }^{22}$ and damages the basal lamina resulting in impaired epithelial restitution..$^{23}$ In addition, the activity of pepsin is $\mathrm{pH}$ dependent and is inhibited at high $\mathrm{pH}$. Whatever the mechanism, the observations presented here strongly support the hypothesis that gastric acid is crucial in the genesis of aspirin- (and possibly other non-steroidal anti-inflammatory drug-) related gastroduodenal injury. Our data show that the reduction in gastric mucosal bleeding rate bears a close relationship to the intragastric $\mathrm{pH}$ achieved with omeprazole. In this context, it is notable that patients with pernicious anaemia and resultant achlorhydria are resistant to aspirin injury compared with healthy controls. ${ }^{2+}$ Even with achlorhydria, however, there was slight injury, possibly because aspirin itself acted as a source of exogenous acid. ${ }^{2+}$

It is possible, however, that oral omeprazole protects the gastric mucosa by additional acid independent mechanisms. In animals, omeprazole given by the oral route is much more effective than when given parenterally in preventing aspirin induced gastric damage despite complete inhibition of gastric acid. ${ }^{25}{ }^{26}$ In addition, oral omeprazole protects against ethanol induced gastric damage if given between 15 to 60 minutes before ethanol, there being no effect evident $3.5 \mathrm{~h}$ after the dose. This protective effect of omeprazole is not mediated through gastric mucosal prostaglandins, ${ }^{27}$ changes in gastric mucosal blood flow, ${ }^{28}$ or alterations in gastric mucosal bicarbonate secretion. ${ }^{29}$ It may be the result of a direct effect of omeprazole on the vascular endothelium, ${ }^{30}$ as omeprazole also protects human gastric epithelial cells in vitro from indomethacin induced damage. ${ }^{31}$

From these and previous data it is clear that aspirin remains injurious to the human gastric mucosa until $\mathrm{pH}$ values approaching neutrality are reached. Greater suppression of acid may be needed to protect the gastroduodenal mucosa against aspirin and other non-steroidal antiinflammatory drugs than is adequate for ulcer healing. Profound suppression of acid, however, may not be without risk. An increased incidence of enteric infection is recognised but this is nonetheless relatively uncommon. At neutral $\mathrm{pH}$ (however achieved) serum gastrin concentrations are raised. ${ }^{32}$ Whether there is a real risk of gastric carcinoid tumours in man given omeprazole is much less clear. There is no evidence in man that the small rises in plasma gastrin seen with gastric antisecretory drugs ${ }^{32}$ produce any sustained hyperplastic change in enterochromaffin like cells. ${ }^{33}$ For the frail elderly patient at high risk of developing aspirin or other non-steroidal anti-inflammatory drug associated ulceration, bleeding, perforation or death the benefits of profound acid suppression with omeprazole are likely to outweigh the risks of enterochromaffin like cell carcinoid tumour development. Although our study showed a statistically significant advantage of omeprazole $40 \mathrm{mg}$ bd over omeprazole $20 \mathrm{mg}$ each morning in reducing gastric mucosal bleeding, the higher dose may not necessarily confer a clinical advantage. A clinical trial of this approach, using omeprazole $20 \mathrm{mg}$ once per day, would therefore be justified in patients at risk of gastric damage from aspirin and non-steroidal anti-inlammatory drugs. Recent prospective studies in patients have shown that ranitidine ${ }^{34}$ and misoprostol ${ }^{35}$ attenuate the damaging effects of non-steroidal anti-inflammatory drugs on the upper gastrointestinal tract. Ranitidine, however, has a preferential protective effect on the duodenum but did not protect against drug induced gastric ulceration, ${ }^{34}$ while the converse was true of misoprostol..$^{35}$ In this context, it is possible that omeprazole may possess an advantage (as yet untested) because of its more potent acid inhibiting action and be capable of attenuating nonsteroidal anti-inflammatory drug induced damage in both stomach and duodenum.

These data were presented to the British Society of Gastroenterology Autumn Meeting: Sheffield September 14-16, 1988. We thank Dr Keith Gillon and Astra Clinical Research Unit, Edinburgh, for supply of study medication and financial support. 
1 Coggan D, Langman MJS, Spiegelhalter D. Aspirin, paracetamol and trematemes cetamo 340 .

2 Collier DS, Pain JA. Non-steroidal antiinflammatory drugs and peptic ulcer perforation. Gut 1985; 26: 359-63.

3 Somerville KW, Faulkner G, Langman MJS. Non-steroidal anti-inflammatory drugs and bleeding peptic ulcer. Lancet 1986; i: 462-4.

4 Walt RP, Katchinski B, Faulkner G, Logan RFA, Langman MJS. Non-steroidal anti-inflammatory drugs and bleeding peptic ulcer. Lancet 1986; i: 489-92.

5 Armstrong CP, Blower AL. Peptic ulcer complications and non-steroidal antiinflammatory drugs [Abstract]. Gut 1986; 27: A609.

6 Hawkey CJ, Prichard PJ, Somerville KH. Strategies for preventing aspirin-induced gastric bleeding. Scand $\mathcal{f}$ preventing aspirin-induced gastric ble
Gastroenterol 1986; 21 [suppl 125]: 170-3.

7 Johnson PC. Gastrointestinal consequences of treatment with drugs in elderly patients. Am Geriatr Soc 1982; 30: w52-5-57.

8 Kitchingman GK, Prichard PJ, Daneshmend TK, Walt RP, Hawkey CJ. Human gastric mucosal bleeding induced by aspirin $300 \mathrm{mg}$ and its prevention by ranitidine [Abstract]. Gut 1988; 29: A711.

9 Daneshmend TK, Prichard PJ, Bhaskar NK, Millns PJ, Hawkey CJ. The use of microbleeding and an ultra-thin endoscope to assess gastric mucosal protection by famotidine. Gastroenterology. 1989; 97: 944-9.

10 Clissold SP, Campoli-Richards DM. Omeprazole: a preliminary review of its pharmacodynamic and pharmacokinetic properties, and therapeutic potential in peptic ulcer disease and Zollinger-Ellison syndrome. Drugs 1986; 32: disease

11 Hunt JN. A procedure for measuring gastric bleeding caused by drugs. Dig Dis Sci 1977; 24: 525-8.

12 Hawkey CJ, Simpson G, Somerville KW. Reduction by enprostil of aspirin-induced blood loss from human gastric mucosa. $A m \mathcal{F} M e d$ 1986; 81 [suppl 2A]: 50-3

13 Douthwaite AH, Lintott GAM. Gastroscopic observations of the effects of aspirin and certain other substances on the stomach. Lancet 1938; ii: 1222-5.

14 Prichard PJ, Somerville KW, Faulkner G, Langman MJS [Abstract]. Gut 1987; 28: Al401.

15 Prichard PJ, Kitchingman GK, Hawkey CJ. Gastric mucosal bleeding: what dose of aspirin is safe? [Abstract]. Gut 1987 28: A1401.

16 Hetzel DJ, Shearman DJC. Omeprazole inhibition of nocturnal gastric secretion in patients with duodenal ulcer. $\mathrm{Br} \mathcal{F}$ Clin Pharmacol 1984; 18: 587-90.

17 Bigard M-A, Isal J-P. Complete prevention by omeprazole of aspirin-induced gastric lesions in healthy subjects of aspirin-induced gastric lesio

18 Flower RJ, Moncada S, Vane JR. Analgesic-antipyretics and anti-inflammatory agents: drugs employed in the treatment of gout. In: Gilman AG, Goodman LS, Rall TW, Murad F, eds. The Pharmacological basis of therapeutics. 7 th ed. New York: Macmillan, 1985: 674-715.
19 Davenport HW. Gastric mucosal haemorrhage in dogs. Effects of acid aspirin and alcohol. Gastroenterology 1969; 56: 43949.

20 Hawkey CJ, Rampton DS. Prostaglandins and the gastrointestinal mucosa: are they important in its function, disease or treatment? Gastroenterology 1985; 89: 1161-88.

21 Spenney JG, Marshall G. Uptake and intracellular concentration of salicylate and p-hydroxybenzoate in in-vitro fundic gastric mucosa. Gastroenterology 1883; 84: 1318

22 Morris GP, Wallace JL. The roles of ethanol and of acid in the production of gastric mucosal erosions in rats. Virchows Arch Cell Pathol) 1981; 32: 23-8.

23 Black BA, Morris GP, Wallace JL. Effects of acid on the basal lamina of the rat stomach and duodenum. Virchows Arch (Cell Pathol) 1985; 50: 109-18.

24 St John DJB, McDermott FT. Influence of achlorhydria on aspirin-induced occult gastrointestinal bleed loss: studies in aspirin-induced occult gastrointestinal bleed loss
pernicious anaemia. $\mathrm{BrMed} \mathcal{F}$ 1970; $2: 450-2$.

25 Mattsson $\mathrm{H}$, Andersson $\mathrm{K}$, Larsson $\mathrm{H}$. Omeprazole provides protection against experimentally induced gastric mucosal protection against experimentally induced

26 Kollberg B, Isenberg JI, Johansson C. Oral omeprazole protects gastric mucosa against ethanol. Gastroenterology 1983; 84: 1212 .

27 Konturek SJ, Brzozowski T, Radecki T. Protective action of omeprazole, a benzimidazole derivative, on gastric mucosal damage by aspirin and ethanol in rats. Digestion 1983; 27: 159-64.

28 Mattsson $\mathbf{H}$, Larsson $\mathbf{H}$. Effect of omeprazole on gastric mucosal blood flow in the rat. Scand $\mathcal{F}$ Gastroenterol 1986; 21 [suppl 118]: 72-4.

29 Mattson H, Carlsson K, Carlsson E. Omeprazole is devoid of effect on alkaline secretion in isolated guinea pig antral mucosa. In: Allen, Flemstrom, Garner, Silen, Turnbrg, eds. mucosa. In: Allen, Flemstrom, Garner, Silen, Turnbrg, eds. Mechanisms of mucosal protection in the upper

30 Mattsson H. Protective effects of omeprazole in gastric mucosa. Scand F Gastroenterol 1986; 21 [suppl 118]: 86-8.

31 Romano M, Razandi M, Ivey KJ. Cimetidine and omeprazole directly protect human gastric epithelial cells in vitro. Gastroenterology 1987; 92: 1599.

32 Lanzon-Miller S, Pounder RE, Hamilton MR, et al. Twentyfour-hour intragastric acidity and plasma gastrin concentration in healthy subjects and patients with duodenal or gastric ulcer or pernicious anaemia. Aliment Pharmacol Ther 1987; 1: 225-37.

33 Lamberts R, Creutzfeldt W, Stockmann F, Jacubaschke U, Mass S, Brunner G. Long-term omeprazole treatment in man: effects on gastric endocrine cell populations. Digestion 1988; 39: 126-35.

34 Ehsanullah RSB, Page MC, Tildesley G, Wood JR. Prevention of gastroduodenal damage induced by non-steroidal anti-
inflammatory drugs: controlled trial of ranitidine. $\mathrm{Br} \mathrm{Med} \mathcal{F}$ inflammatory drugs:

35 Graham DY, Agrawal NM, Roth SH. Prevention of NSAIDinduced gastric ulcer with misoprostol: multicentre, doubleblind, placebo-controlled trial. Lancet 1988; ii: 1277-80. 